\title{
Fractures of the Clavicle: An Overview
}

\author{
Thomas D. Donnelly ${ }^{*}$, Robert J. MacFarlane, Mathias Thomas Nagy, Peter Ralte and \\ Mohammad Waseem
}

\author{
Department of Trauma and Orthopaedics, Macclesfield District General Hospital, Victoria Road, Macclesfield, SK10 \\ $3 B L, U K$
}

\begin{abstract}
Fractures of the clavicle are a common injury and most often occur in younger individuals. For the most part, they have been historically treated conservatively with acceptable results. However, over recent years, more and more research is showing that operative treatment may decrease the rates of fracture complications and increase functional outcomes. This article first describes the classification of clavicle fractures and then reviews the literature over the past decades to form a conclusion regarding the appropriate management.
\end{abstract}

A thorough literature review was performed on assessment of fractures of the clavicle, their classification and the outcomes following conservative treatment. Further literature was gathered regarding the surgical treatment of these fractures, including the methods of fixation and the surgical approaches used. Both conservative and surgical treatments were then compared and contrasted.

The majority of recent data suggests that operative treatment may be more appropriate as it improves functional outcome and reduces the risk of complications such as non-union. This is particularly evident in mid shaft fractures, although more high grade evidence is needed to fully recommend this, especially regarding certain fractures of the medial and lateral clavicle.

Keywords: Clavicle fracture, internal fixation, locking plate, Rockwood pin.

\section{INTRODUCTION}

Fractures of the clavicle are common injuries accounting for between 2.6 and $4 \%$ of adult fractures and $35 \%$ of injuries to the shoulder girdle [1-3]. Early reports of clavicle fractures date back to Hippocrates [4], who noted that "when a fractured clavicle is fairly broken across it is more easily treated, but when broken obliquely it is more difficult to manage". Clavicular fractures are most common in younger patients with incidence greatest in the second and third decades. The prevalence of fractures to the clavicle has been seen to decrease with every decade, after a patient is 20 years of age. However, the ratio of female to male increases with age. The aetiology of clavicle injuries in young adults and children is most commonly an RTA, sports injury and, to a lesser extent, a fall. However, falls represent their most frequent cause among the elderly [3]. Clavicle injuries can be grossly divided into three distinct anatomical sites; the medial clavicle, shaft and lateral end. Mid-shaft clavicle [1, $3]$ fractures are most common, with an incidence of up to $82 \%$ of all clavicle fractures. Medial and lateral end fractures account for approximately 18 and $2 \%$ respectively [3]. The location and pattern of injury are of considerable importance when formulating a management plan.

There has been an increase in treatment options available andin the frequency with which clavicle fractures are treated

*Address correspondence to this author at the Department of Trauma and Orthopaedics, Macclesfield District General Hospital, Victoria Road, Macclesfield, SK10 3BL, UK; Tel: 01625 661099; Fax: 01625 661436; E-mail: tdonnelly@doctors.org.uk operatively. A number of technical challenges exist for the operating surgeon and clinical results for a range of methods of treatment have been variable. Here we summarise the assessment and management of fractures of the clavicle, providing an overview of the clinical results of a range of treatment options.

\section{CLASSIFICATION}

A number of classification systems have been described for the classification of clavicle fractures [1, 5-7]. Allman [5] divided clavicle fractures by anatomical site into 3 groups; group 1 being fractures to the middle third, group 2 being fractures distal to the coraco-clavicular ligament, and Group 3 relating to fractures of the proximal third of the clavicle [5]. Neer [6] went further and subdivided lateral third fractures into three groups; undisplaced, displaced, and intraarticular. The displaced types were then divided into $2 \mathrm{a}$ or $2 \mathrm{~b}$, depending on the presence of injury to the coracoclavicular (CC) ligaments [6]. Thus a type 2 a injury represents a fracture medial to both conoid and trapzezoid elements of the $\mathrm{CC}$ ligaments, with the shaft displacing superior relative to the lateral end. A type $2 b$ injury represents a fracture of the lateral end of the clavicle, with disruption of the conoid portion of the CC ligament [6]. Robinson [1] was the first to describe clavicle fractures in relation to their displacement and degree of comminution, via the Edinburgh classification. He then used his parameters to predict the risk of non-union, in such fractures, with good affect [7]. The Edinburgh classification system has been shown to provide more reliable prognostic information in 
middle third fractures, in comparison to other classification systems.

\section{ASSESSMENT}

After detailing the history of the presenting complaint, including the mechanism of injury, a thorough clinical examination should be performed. The examination should include both shoulders and the arm, to exclude any vascular or brachial plexus injury. Differing limb blood pressures may be present if there is a vascular injury and, if clinically suspected, a duplex or angiogram should be arranged. Upon inspection, it is important to note any skin tenting or punctures, as well as the presence of ecchymosis, around the fracture site. The fracture may have a striking deformity, particularly if it is a displaced mid-shaft fracture, as the weight of the shoulder/arm pulls the lateral fragment caudally, whilst the sternocleidomastoid muscle pulls the medial end in a cephalad direction. An assessment of the neurovascular status of the affected limb is mandatory. Patients should also have a plain antero-posterior (AP) X-ray performed in the emergency department. In fractures of the medial third, a plain $\mathrm{x}$ ray may be inconclusive and it is not difficult to confuse a fracture with sterno-clavicular dislocation. Moreover, AP radiographs may provide the viewing clinician with little or no information regarding the degree of posterior displacement of the clavicle in medial third injuries, which may affect the mediastinal or apical structures. Other projections of the clavicle may be performed after liaising with a radiographer, such an apical oblique view of the clavicle with the patient standing at 45 degrees toward the beam and the beam angled 20-30 degrees cephalad. In addition, computed tomography (CT) of the clavicle with 3D reconstruction has been shown to be a useful diagnostic aid [8].

\section{TREATMENT}

The majority of clavicle fractures are treated nonoperatively with good outcomes [9-12]. Measures such as an arm sling, analgesia and, in the case of mid shaft fractures, a figure of eight bandage across the shoulders, often provide ample treatment. Early comparisons of conservative and operative measures were in favour of conservative treatment. Neer [11], in a retrospective review of 18 cases of clavicle non-union, and Rowe [12] both demonstrated an increased rate of non-union following open reduction and internal fixation of clavicular shaft fractures. More recently, there has been a trend towards an increased rate of operative intervention, particularly in mid-shaft fractures. A number of authors have demonstrated lower rates of complications, such as pain, non-union and instability. Furthermore, improved functional outcomes have been demonstrated in patients having operative management compared with conservative measures[10, 13]

\section{MID SHAFT CLAVICULAR FRACTURES}

Undisplaced mid-shaft fractures are generally managed non-operatively. Displaced or angulated fractures, which are closed injuries, are also usually managed by conservative means. The use of a simple arm sling and the figure of eight bandage are the most widely reported methods of conservative management for a mid-shaft fracture of the clavicle. In 1987 Andersen et alreported less discomfort and a trend towards fewer complications with a sling and similar clinical and functional results with either a sling or a figure of 8 bandage [14]. The Cochrane review in 2009 has recommended that further research is warranted in this area to form an appropriate conclusion [15].

Until recent years, both slings and figure of 8 bandages were used as accepted methods of treatment for displaced fractures. Altimimi et al reported the results of a multicentre prospective randomized trial in 2009, comparing nonoperative treatment and internal fixation in 132 patients with displaced midshaft fractures of the clavicle. They demonstrated improved functional scores, lower pain scores, shorter time to union and greater patient satisfaction at all time points up to one year after surgical fixation in the group treated with a plate [13]. Despite this, the operative group had a complication rate of $34 \%$ and a reoperation rate of $18 \%$. Complications included local irritation, prominence of hardware, plate failure and wound infection. The reoperations were predominantly for the removal of the hardware. It is widely accepted that, due to complication rates with primary operative treatment and the satisfactory results of the operative treatment of nonunion or malunion, many displaced fractures should be treated conservatively with care taken not to over treat [16]. Many clinicians reserve operative treatment for open injuries, or those with significant skin tenting, and fractures in which the initial shortening is $>20 \mathrm{~mm}$; a characteristic associated with high nonunion rates if treated conservatively [17]. More research is needed to gather level I and II data, to produce guidelines on whether fixation is suitable for all displaced mid-shaft fractures.

A recent meta-analysis [18] of randomized trials, comparing operative and non-operative treatment, has supported previous data demonstrating significantly lower rates of non-union and mal-union, with an earlier return of function, in midshaft fractures treated with internal fixation. However, the long-term functional benefits of internal fixation remain unclear.

A range of implants are available on the market for internal fixation of diaphyseal fractures, broadly divided into plate/ screw configurations and intramedullary devices. The use of dynamic compression plates (DCP) [19], locking plates (LP) [20] and reconstruction plates [21] have all been reported in the literature. Reconstruction plates have largely fallen out of favour due to their weakness and potential to deform at the site of the fracture leading to mal-union. The use of locking plate devices provides stability of the fracture, pain relief and facilitates early mobilization of the shoulder [22].

A number of authors have examined the comparative biomechanical properties of plates and intramedullary devices for diaphyseal clavicle fractures. Golish et al. demonstrated that plate fixation provides a superior construct, demonstrating decreased displacement at fixed loads, as well as greater loads at fixed levels of displacement during a wider range of movements. This may be of benefit in early/ accelerated rehabilitation protocols [23]. In the presence of comminution, which is usually inferior, locking plates are advantageous as their position on the superior aspect of the clavicle bestows greater stability than an intramedullary device [24]. Surgeons must be aware, 
however, of a greater risk of injury to the underlying neurovascular structures from drilling and manipulation of the fracture. Alternative approaches have been reported with an antero-inferior approach associated with low nonunion and infection rates and an excellent return to function [25]. Testing of this biomechanically, against a superior position, has shown that a superior plate position may provide a more secure fixation of the fracture. Pre-contoured locking plates may be less prominent after healing and may lead to less incidence of hardware removal [20]. The complications associated with plate fixation are; infection, non-union, malunion, further surgery, scarring, re-fracture after plate removal and intra-operative vascular injury [26, 27]. Intramedullary fixation has been shown to result in fewer complications, as it preserves the soft tissue envelope and periosteum, as well as being cosmetically more pleasing [28].

Because of the sigmoid shape of the clavicle, intramedullary fixation of fractures has traditionally been difficult. Static locking is not available on current devices. The implant has to be small enough to negotiate the narrow intra-medullary canal and the sigmoid bend in the clavicle, whilst still being strong enough to cope with the forces across the fracture until bone union [29]. There are a wider range of devices for intra-medullary fixation of the clavicle including; Knowles pins [30], Rockwood pins [31], Hagie pins [10] or titanium elastic nails [28]. Two principal methods for device insertion exist: antegrade via an anteromedial entry point, and retrograde via a postero-lateral entry point. Clinical results of intra-medullary fixation have been varied [10, 32]. However, the potential benefits are well known such as minimal tissue dissection and soft tissue stripping, leading to less disruption to the periosteal blood supply. Intra-medullary fixation also avoids the development of stress risers, caused by the removal of multiple screws during plate removal, thereby minimizing the likelihood of a re-fracture. However, complications such as hardware breaks, nerve injury and skin breakdown have been reported $[33,34]$ as well as hardware migration and injury to infraclavicular structures [35]. In the absence of static locking, there may be shortening of the clavicle over time, a problem that is more likely in comminuted fractures. This complication is particularly associated with unthreaded devices such as Kirschner wires or Titanium nails [33, 36], but it has also been reported in threaded Kirschner wires and a Hagie pin [35].

Clinical results with intramedullary fixation are variable and many surgeons prefer plate fixation for primary operative treatment of clavicle fractures or non-unions. It is worth noting, however, that intramedullary fixation is also useful in those patients with multiple injuries or additional shoulder pathologies, due to its minimally invasive approach [37]. As an alternative to internal fixation, external fixators may be also used in certain circumstances, although these are only recommended for use in open fractures or in the case of a septic non-union [38].

\section{LATERAL END FRACTURES}

Undisplaced fractures of the lateral end of the clavicle (Neer type 1, Edinburgh type 3A) are generally treated conservatively as they have an intact periostial sleeve and are relatively stable, due to the intact conoid and trapezoid CC ligaments [11]. Good results have been reported with conservative measures [39] using analgesia and an arm sling. Occasionally these fractures may have an intra-articular component, which can cause late pain and/or stiffness. If problematic, the small distal fragment can be removed surgically with favourable outcomes $[11,39]$.

Displaced lateral clavicle fractures are often treated operatively $[6,39]$ with conservative measures being associated with high rates of non-union [1, 5, 6, 39]. A systematic review of lateral clavicle fractures, published in 2010 , reported a $33.3 \%$ non-union rate in conservatively managed injuries and a $6 \%$ nonunion rate in those treated operatively [40]. Non-operative treatment is generally used in those patients who are low demand, elderly or frail [41]. An increase in the incidence of lateral clavicle fractures is seen in elderly patients and conservative management in this age-group is not associated with significant functional loss in the presence of a non-union [42]. For the majority of younger patients with these fractures, operative treatment is more appropriate. A range of techniques are described for fixation of these injuries including; plating (hook-plate, locking $\mathrm{T}$ plates) [43, 44], coraco-clavicular screw [45], Kirschner wires [46] and Knowles pins [47].

In the case of a standard distal clavicle plate, three screws (a minimum of two) should be placed in the distal fragment to provide sufficient stability [48]. The relatively recent introduction of contoured plates (such as the locking $\mathrm{T}$ plate) allows more screws to be placed in the distal fragment, which may improve stability [49]. Clinicial results with precontoured plating systems have been positive, with a number of authors reporting good functional outcomes and few complications [43, 50, 51]. Martetschlager et al. [43] treated 30 patients with a locking $\mathrm{T}$ plate and supplementary PDS circlage suturing, achieving union within 10 weeks and good or excellent functional outcomes with a return to premorbid levels of activity in all cases. These results were supported in a recent report by Kang et al. [50] in a group of 10 patients with non-unions of the distal lend of the clavicle. Mean time to union was 14 weeks, with all patients demonstrating good or excellent functional scores at final follow up of 24 months.

The hook-plate was specifically engineered for acromioclavicular injuries, such as dislocations, as well as to provide operative treatment for fractures with a small distal fragment where other plating techniques would be inappropriate [52]. Good et al. prospectively reviewed 36 cases of distal clavicle fracture that underwent hook plate fixation as a primary procedure. Mean time to union was 3 months with a union rate of $95 \%$ [44]. In a recent study by Tiren at al, 28 patients were managed primarily with a hook plate, achieving union in all but 1 case (96\%). At a mean follow up time of 5.4 years, the mean Constant functional score was 97 with mean DASH scores 3.5. The authors noted a $32 \%$ incidence of subacromial impingement and a $25 \%$ rate of subacromial osteolysis. In all cases, symptoms resolved following removal of the plate allows early mobilization and good subjective and objective functional outcome. The presence of subacromial impingement, or osteolysis, may be due to anatomical variations in the acromion and lateral clavicle. 
Problems can be avoided by bending the plate slightly to fit the patient [53].

Coraco-clavicular screws have been described, as far back as 1941 by Bosworth, as a method of treatment for acromio-clavicular separation [54]. This type of fixation is relatively widely used, with a number of studies demonstrating encouraging results [55]. It is worth noting that this procedure can be technically demanding because of the small area of coracoid that is available for screw insertion, which is associated with a higher rate of fixation failure [16]. Kirschner wiring has been used in the past but, as with mid-clavicular fractures, there are problems with pin migration [56] as well as non-union and infection [57].

Surgical techniques, involving sutures and or ligament grafts, have been used either alone or alongside primary fixation to good affect [58]. This is implemented by looping sutures around the coracoid process and the distal clavicle, or by drilling holes within the clavicle. The 'tightrope technique,' which involves two EndoButtons in the clavicle and coracoid, and a loop of suture material through these, has been described as also demonstrating good early results for use in both fractures and dislocations [51, 59]. This also has the added advantage of there being no need for implant removal.

Lateral end fractures, involving the articular surface (Neer 3, Edinburgh $3 \mathrm{~A} 2$ and 3B2), are relatively rare and make up around $3.3 \%$ of clavicular fractures [1]. These are normally treated similarly to non-articular lateral fractures, depending on the amount of displacement [16].

\section{MEDIAL END FRACTURES}

Fractures of the medial clavicle (Edinburgh 1) are rare and account for approximately $2 \%$ of all clavicle fractures. Despite their rarity, these fractures can be dangerous due to damage to the neurovascular structures situated posteriorly [8]. It is important to ascertain, both clinically and by radiological imaging, if the injury is an acute fracture or an epiphseal separation, which can remain open until 30 years of age. Approximately $80 \%$ of the length of the adult clavicle comes from the medial growth plate [60]. The stability of this type of fracture is maintained by the costoclavicular ligaments. If these are affected, the fracture is more likely to be unstable [5]. Because of the close proximity of the mediastinal structures, formal fixation is considered only in the event of marked displacement of the clavicle, with a risk to underlying structures $[8,61]$.

\section{CONCLUSION AND RECOMMENDATIONS}

Clavicular fractures are common and they predominantly affect the younger age group. The decision on treatment should be made in conjunction with the patient, taking into account their age, comorbidities, fracture classification, soft tissue injury and individual surgeon and patient preferences. Although traditionally these fractures have been treated nonoperatively with acceptable results, there is now good evidence which demonstrates improved functional outcome with internal fixation. Furthermore, a reduced risk of nonunion and symptomatic malunion is also seen in cases undergoing operative treatment, particularly for fractures of the diaphysis. Further work is required in the form of prospective comparative data, examining methods for fixation and conservative measures in both medial and lateral end fractures.

\section{CONFLICT OF INTEREST}

The authors confirm that this article content has no conflict of interest.

\section{ACKNOWLEDGEMENTS}

Ms Kelly Graham helped significantly in final editing and proof reading of the manuscript including the correction of many syntax and grammatical errors.

\section{REFERENCES}

[1] Robinson CM. Fractures of the clavicle in the adult. Epidemiology and classification. J Bone Joint Surg Br 1998; 80(3): 476-84.

[2] Nordqvist A, Petersson C. The incidence of fractures of the clavicle. Clin Orthop Relat Res 1994; 300: 127-32.

[3] Postacchini F, Gumina S, De Santis P, Albo F. Epidemiology of clavicle fractures. J Shoulder Elbow Surg 2002; 11(5): 452-6.

[4] Hippocrates. On The Articulations. 400 B.C.E.

[5] Allman FL, Jr. Fractures and ligamentous injuries of the clavicle and its articulation. J Bone Joint Surg Am 1967; 49(4): 774-84.

[6] Neer CS, $2^{\text {nd. }}$ Fractures of the distal third of the clavicle. Clin Orthop Relat Res 1968; 58: 43-50.

[7] Robinson CM, Court-Brown CM, McQueen MM, Wakefield AE. Estimating the risk of nonunion following nonoperative treatment of a clavicular fracture. J Bone Joint Surg Am 2004; 86-A(7): 1359-65.

[8] Hanby CK, Pasque CB, Sullivan JA. Medial clavicle physis fracture with posterior displacement and vascular compromise: the value of three-dimensional computed tomography and duplex ultrasound. Orthopedics 2003; 26(1): 81-4.

[9] Nordqvist A, Petersson CJ, Redlund-Johnell I. Mid-clavicle fractures in adults: end result study after conservative treatment. J Orthop Trauma 1998; 12(8): 572-6.

[10] Grassi FA, Tajana MS, D'Angelo F. Management of midclavicular fractures: comparison between nonoperative treatment and open intramedullary fixation in 80 patients. J Trauma 2001; 50(6): 1096100 .

[11] Neer CS, $2^{\text {nd. }}$ Nonunion of the clavicle. J Am Med Assoc 1960; 172: 1006-11.

[12] Rowe CR. An atlas of anatomy and treatment of midclavicular fractures. Clin Orthop Relat Res 1968; 58: 29-42.

[13] Altamimi SA, McKee MD. Nonoperative treatment compared with plate fixation of displaced midshaft clavicular fractures. Surgical technique. J Bone Joint Surg Am 2008; 90(Suppl 2: Pt 1): 1-8.

[14] Andersen K, Jensen PO, Lauritzen J. Treatment of clavicular fractures. Figure-of-eight bandage versus a simple sling. Acta Orthop Scand 1987; 58(1): 71-4.

[15] Lenza M, Belloti JC, Andriolo RB, Gomes Dos Santos JB, Faloppa F. Conservative interventions for treating middle third clavicle fractures in adolescents and adults. Cochrane Database Syst Rev 2009; (2): CD007121.

[16] Khan LA, Bradnock TJ, Scott C, Robinson CM. Fractures of the clavicle. J Bone Joint Surg Am 2009; 91(2): 447-60.

[17] Hill JM, McGuire MH, Crosby LA. Closed treatment of displaced middle-third fractures of the clavicle gives poor results. J Bone Joint Surg Br 1997; 79(4): 537-9.

[18] McKee RC, Whelan DB, Schemitsch EH, McKee MD. Operative versus nonoperative care of displaced midshaft clavicular fractures: a meta-analysis of randomized clinical trials. J Bone Joint Surg Am 2012; 94(8): 675-84.

[19] Kabak S, Halici M, Tuncel M, Avsarogullari L, Karaoglu S. Treatment of midclavicular nonunion: comparison of dynamic compression plating and low-contact dynamic compression plating techniques. J Shoulder Elbow Surg 2004; 13(4): 396-403.

[20] Huang JI, Toogood P, Chen MR, Wilber JH, Cooperman DR. Clavicular anatomy and the applicability of precontoured plates. J Bone Joint Surg Am 2007; 89(10): 2260-5.

[21] Shen JW, Tong PJ, Qu HB. A three-dimensional reconstruction plate for displaced midshaft fractures of the clavicle. J Bone Joint Surg Br 2008; 90(11): 1495-8. 
[22] Bradbury N, Hutchinson J, Hahn D, Colton CL. Clavicular nonunion. 31/32 healed after plate fixation and bone grafting. Acta Orthop Scand 1996; 67(4): 367-70.

[23] Golish SR, Oliviero JA, Francke EI, Miller MD. A biomechanical study of plate versus intramedullary devices for midshaft clavicle fixation. J Orthop Surg Res 2008; 3: 28.

[24] Iannotti MR, Crosby LA, Stafford P, Grayson G, Goulet R. Effects of plate location and selection on the stability of midshaft clavicle osteotomies: a biomechanical study. J Shoulder Elbow Surg 2002; 11(5): 457-62.

[25] Collinge C, Devinney S, Herscovici D, DiPasquale T, Sanders R. Anterior-inferior plate fixation of middle-third fractures and nonunions of the clavicle. J Orthop Trauma 2006; 20(10): 680-6.

[26] Bostman O, Manninen M, Pihlajamaki H. Complications of plate fixation in fresh displaced midclavicular fractures. J Trauma 1997; 43(5): 778-83.

[27] Kuner EH, Schlickewei W, Mydla F. Surgical therapy of clavicular fractures, indications, technic, results. Hefte Unfallheilkd 1982; 160: $76-83$.

[28] Liu PC, Chien SH, Chen JC, Hsieh CH, Chou PH, Lu CC. Minimally invasive fixation of displaced midclavicular fractures with titanium elastic nails. J Orthop Trauma 2010; 24(4): 217-23.

[29] Andermahr J, Jubel A, Elsner A, Johann J, Prokop A, Rehm KE, Koebke J. Anatomy of the clavicle and the intramedullary nailing of midclavicular fractures. Clin Anat 2007; 20(1): 48-56.

[30] Lee Y, Lin CC, Huang CR, Chen CN, Liao WY. Operative treatment of midclavicular fractures in 62 elderly patients: knowles pin versus plate. Orthopedics 2007; 30(11): 959-64

[31] Mudd CD, Quigley KJ, Gross LB. Excessive complications of open intramedullary nailing of midshaft clavicle fractures with the Rockwood Clavicle Pin. Clin Orthop Relat Res 2011; 469(12): 3364-70.

[32] Neviaser RJ, Neviaser JS, Neviaser TJ. A simple technique for internal fixation of the clavicle. A long term evaluation. Clin Orthop Relat Res 1975; (109): 103-7.

[33] Strauss EJ, Egol KA, France MA, Koval KJ, Zuckerman JD. Complications of intramedullary Hagie pin fixation for acute midshaft clavicle fractures. J Shoulder Elbow Surg 2007; 16(3): 280-4.

[34] Ring D, Holovacs T. Brachial plexus palsy after intramedullary fixation of a clavicular fracture. A report of three cases. J Bone Joint Surg Am 2005; 87(8): 1834-7.

[35] Sethi GK, Scott SM. Subclavian artery laceration due to migration of a Hagie pin. Surgery 1976; 80(5): 644-6.

[36] Kettler M, Schieker M, Braunstein V, König M, Mutschler W. Flexible intramedullary nailing for stabilization of displaced midshaft clavicle fractures: technique and results in 87 patients. Acta Orthop 2007; 78(3): 424-9.

[37] Jubel A, Andermahr J, Schiffer G, Tsironis K, Rehm KE. Elastic stable intramedullary nailing of midclavicular fractures with a titanium nail. Clin Orthop Relat Res 2003; (408): 279-85.

[38] Schuind F, Pay-Pay E, Andrianne Y, Donkerwolcke M, Rasquin C, Burny F. External fixation of the clavicle for fracture or non-union in adults. J Bone Joint Surg Am 1988; 70(5): 692-5.

[39] Nordqvist A, Petersson C, Redlund-Johnell I. The natural course of lateral clavicle fracture. 15 (11-21) year follow-up of 110 cases. Acta Orthop Scand 1993; 64(1): 87-91.

[40] Oh JH, Kim SH, Lee JH, Shin SH, Gong HS. Treatment of distal clavicle fracture: a systematic review of treatment modalities in 425 fractures. Arch Orthop Trauma Surg 2011; 131(4): 525-33.

[41] Bisbinas I, Mikalef P, Gigis I, Beslikas T, Panou N, Christoforidis I. Management of distal clavicle fractures. Acta Orthop Belg 2010; 76(2): 145-9.
[42] Robinson CM, Cairns DA. Primary nonoperative treatment of displaced lateral fractures of the clavicle. J Bone Joint Surg Am 2004; 86-A(4): 778-82.

[43] Martetschläger F, Kraus TM, Schiele CS, et al. Treatment for unstable distal clavicle fractures (Neer 2) with locking T-plate and additional PDS cerclage. Knee Surg Sports Traumatol Arthrosc 2013; 21(5): 1189-94.

[44] Good DW, Lui DF, Leonard M, Morris S, McElwain JP. Clavicle hook plate fixation for displaced lateral-third clavicle fractures (Neer type II): a functional outcome study. J Shoulder Elbow Surg 2012; $21(8)$ : 1045-8.

[45] Esenyel CZ, Ceylan HH, Ayanoğlu S, Kebudi A, Adanir O, Bülbül M. Treatment of Neer Type 2 fractures of the distal clavicle with coracoclavicular screw. Acta Orthop Traumatol Turc 2011; 45(5): 291-6.

[46] Wu K, Chang CH, Yang RS. Comparing hook plates and Kirschner tension band wiring for unstable lateral clavicle fractures. Orthopedics 2011; 34(11): e718-23.

[47] Jou IM, Chiang EP, Lin CJ, Lin CL, Wang PH, Su WR. Treatment of unstable distal clavicle fractures with Knowles pin. J Shoulder Elbow Surg 2011; 20(3): 414-9.

[48] Hessmann M, Kirchner R, Baumgaertel F, Gehling H, Gotzen L. Treatment of unstable distal clavicular fractures with and without lesions of the acromioclavicular joint. Injury 1996; 27(1): 47-52.

[49] Kalamaras M, Cutbush K, Robinson M. A method for internal fixation of unstable distal clavicle fractures: early observations using a new technique. J Shoulder Elbow Surg 2008; 17(1): 60-2.

[50] Kang HJ, Kim HS, Kim SJ, Yoo JH. Osteosynthesis of symptomatic nonunions of type II fractures of the distal clavicle using modified locking T-plate and bone grafting. J Trauma Acute Care Surg 2012; 72(2): E14-9.

[51] Hohmann E, Hansen T, Tetsworth K. Treatment of Neer type II fractures of the lateral clavicle using distal radius locking plates combined with TightRope augmentation of the coraco-clavicular ligaments. Arch Orthop Trauma Surg 2012; 132(10): 1415-21.

[52] Faraj AA, Ketzer B. The use of a hook-plate in the management of acromioclavicular injuries. Report of ten cases. Acta Orthop Belg 2001; 67(5): 448-51.

[53] Muramatsu K, Shigetomi M, Matsunaga T, Murata Y, Taguchi T. Use of the AO hook-plate for treatment of unstable fractures of the distal clavicle. Arch Orthop Trauma Surg 2007; 127(3): 191-4.

[54] Bosworth BM. Acromioclavicular separation: New method of repair. Surg Gynacol Obstet 1941; 73: 866-71.

[55] Macheras G, Kateros KT, Savvidou OD, Sofianos J, Fawzy EA, Papagelopoulos PJ. Coracoclavicular screw fixation for unstable distal clavicle fractures. Orthopedics 2005; 28(7): 693-6.

[56] Julià D, Baldó X, Gómez N, Mármol E. Transthoracic migration of a Kirschner wire from the humerus to the abdomen. Eur J Cardiothorac Surg 2012; 41(5): 1197-8.

[57] Flinkkilä T, Ristiniemi J, Hyvönen P, Hämäläinen M. Surgical treatment of unstable fractures of the distal clavicle: a comparative study of Kirschner wire and clavicular hook plate fixation. Acta Orthop Scand 2002; 73(1): 50-3

[58] Yang SW, Lin LC, Chang SJ, Kuo SM, Hwang LC. Treatment of acute unstable distal clavicle fractures with single coracoclavicular suture fixation. Orthopedics 2011; 34(6): 172.

[59] Hosseini H, Friedmann S, Tröger M, Lobenhoffer P, Agneskirchner JD. Arthroscopic reconstruction of chronic AC joint dislocations by transposition of the coracoacromial ligament augmented by the Tight Rope device: a technical note. Knee Surg Sports Traumatol Arthrosc $2009 ; 17(1): 92-7$.

[60] Jeray KJ. Acute midshaft clavicular fracture. J Am Acad Orthop Surg $2007 ; 15(4): 239-48$.

[61] Lo EY, Eastman J, Tseng S, Lee MA, Yoo BJ. Neurovascular risks of anteroinferior clavicular plating. Orthopedics 2010; 33(1): 21. 